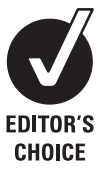
Cardiff University, Cardiff, UK:

${ }^{2}$ School of Computing, Engineering and Physical Sciences, University of Central Lancashire, Preston, UK;

${ }^{3}$ Department of Clinical Genetics, Oxford Radcliffe Hospital, Oxford, UK; ${ }^{4}$ South Australian Clinical Genetics Service, SA Pathology, Women's and Children's, Hospital North Adelaide, and Department of Paediatrics, University of Adelaide, Adelaide, Australia; ${ }^{5}$ Regional Genetic Service, St Mary's Hospital, Manchester, UK

Correspondence to: Professor M Upadhyaya Institute of Medical Genetics, Cardiff University, Heath Park, Cardiff CF14 4XN, UK; Upadhyaya@cardiff.ac.uk

Received 5 December 2008 Revised 12 February 2009

Accepted 13 February 2009 Published Online First

13 May 2009

\title{
SPRED1 mutations (Legius syndrome): another clinically useful genotype for dissecting the neurofibromatosis type 1 phenotype
}

\author{
G Spurlock, ${ }^{1}$ E Bennett, ${ }^{1} \mathrm{~N}$ Chuzhanova, ${ }^{2} \mathrm{~N}$ Thomas, ${ }^{1} \mathrm{H}$-Ping Jim, ${ }^{1} \mathrm{~L}$ Side, ${ }^{3}$ S Davies, \\ E Haan, ${ }^{4}$ B Kerr, ${ }^{5}$ S M Huson, ${ }^{5}$ M Upadhyaya ${ }^{1}$
}

\begin{abstract}
Objective: Mutations of the SPRED1 gene, one of a family of Sprouty (Spry)/Spred proteins known to "downregulate" mitogen activated protein kinase (MAPK) signalling, have been identified in patients with a mild neurofibromatosis type 1 (NF1) phenotype with pigmentary changes but no neurofibromas (Legius syndrome).To ascertain the frequency of SPRED1 mutations as a cause of this phenotype and to investigate whether other SPRED/SPRY genes may be causal, a panel of unrelated mild NF1 patients were screened for mutations of the SPRED1-3 and the SPRY1-4 genes.

Methods: 85 patients with a mild NF1 phenotype were screened for SPRED1 mutations. 44 patients negative for both NF1 and SPRED1 mutations were then screened for SPRED2-3 and SPRY1-4 mutations. Complexity analysis was applied to analyse the flanking sequences surrounding the identified SPRED1 mutations for the presence of direct and inverted repeats or symmetric sequence elements in order to infer probable mutational mechanism.
\end{abstract}

Results: SPRED1 mutations were identified in 6 cases; 5 were novel and included 3 nonsense (R16X, E73X, R262X), 2 frameshift (c.1048 c1049 delGG,

c.149 1152del 4 bp), and a single missense mutation (V44D). Short direct or inverted repeats detected immediately adjacent to some SPRED1 mutations may have led to the formation of the microdeletions and base pair substitutions.

Discussion: The identification of SPRED1 gene mutation in NF1-like patients has major implications for counselling NF1 families.

Neurofibromatosis type 1 (NF1, MIM 162200), is a common autosomal dominantly inherited complex disorder, with a 1/2500 birth incidence and a 1/ 5000 prevalence worldwide. ${ }^{1}$ This disorder exhibits a high mutation rate, with almost half of all NF1 patients being de novo cases of the disease. The cardinal clinical features of NF1 involve pigmentary changes (café-au-lait spots and skinfold freckling), and the development of cutaneous neurofibromas and of hamartomas of the iris (Lisch nodules). ${ }^{12}$ Neurofibromas are outgrowths of the peripheral nerve sheath, and the majority of adult NF1 patients will have multiple cutaneous neurofibromas. Much larger plexiform tumours are also characteristic of this disorder. NF1 is caused by inactivating mutations of the 17q11.2 located NF1 gene that encodes neurofibromin, which functions by tightly controlling cellular levels of active Ras proteins. Any inactivation of neurofibromin therefore leads to prolonged activation of functional Ras proteins, resulting in unregulated increases in cell growth, proliferation and an increased risk of malignancy, identifying NF1 as a tumour suppressor gene. ${ }^{2}$ The NF1 gene therefore represents one of the key regulatory points in the complex RASMAP kinase signalling pathway in the cell. ${ }^{34}$

A small but significant proportion of patients with the NF1 pigmentary phenotype never develop neurofibromas and have been classified as "autosomal dominant café-au-lait spots only" on clinical grounds. The problem is that this diagnosis can only be confidently made in families with two or more generations where the adults have no neurofibromas. We previously reported the same c.2970-2972 delAAT (p.990delM) mutation in exon 17 of the NF1 gene in 21 unrelated probands with this phenotype..$^{5}$ Recently, SPRED1 gene mutations have been reported with the same clinical picture. ${ }^{6}$ The situation is further complicated in that some of these patients also had learning problems and macrocephaly and so in childhood the phenotype is indistinguishable from NF1. The Spred1 protein is a member of the Sprouty (SPRY) family of proteins that function to inhibit the growth factor mediated MAP kinase pathway signalling by interaction with both Ras and Raf1 proteins. ${ }^{7}$ The Spred1 protein contains several distinct domains that enable different Spreds to inhibit specifically the mitogen activated protein kinase (MAPK) pathway. Spred specifically binds to RhoA, Ras, Raf1 and Caveolin-1, thus preventing their activation and suppressing the Ras/MAPK pathway.

Brems et $a^{6}$ identified 11 different SPRED1 mutations in 91 unrelated patients with NF1 pigmentary phenotype. We have screened for SPRED1 mutations in 85 unrelated, NF1 gene mutation negative individuals, none of whom had cutaneous neurofibromas. Six SPRED1 germline mutations were identified of which five were novel changes in these patients. Forty-four of these patients, with neither a SPRED1 nor NF1 mutation, were further screened for mutations in six biologically related genes (SPRED2, SPRED3, SPRY1, SPRY2, SPRY3 and SPRY4).

\section{PATIENTS AND METHODS \\ Patient samples}

Eighty-five unrelated patients referred for NF1 gene testing and found to be NF1 mutation negative, and who did not have cutaneous neurofibromas, were screened for SPRED1 mutations. Limited amounts of DNA meant that only 44 patients 
found to be without either an NF1 or a SPRED1 mutation were subsequently screened for the mutations in six other genes (SPRED2, SPRED3, SPRY1, SPRY2, SPRY3 and SPRY4). ${ }^{9}$

Lymphocyte DNA was extracted and SPRED1 polymerase chain reaction (PCR) carried out using the exon specific primer sequences reported by Brems et al. ${ }^{6}$ For PCR amplification of the SPRED2, SPRED3, SPRY1, SPRY2, SPRY3 and SPRY4 genes the M13 tagged primer sequences and the PCR conditions shown in table 1 were used. The mutation screen applied to all amplified exonic sequences involved direct DNA sequencing (ABI3730 sequencer, Applied Biosystems, Warwick, UK).

An (AT)n microsatellite repeat located in intron 1 of the SPRED1 gene was used to assess gene heterozygosity or homozygosity in each patient. The primer sequences for amplifying this polymorphic marker are: forward: 5'CTTTGAAGTTTGTATGGCATGA $-3^{\prime}$ and reverse: $5^{\prime}$ ACAAATTATCCATTTTCAAGCTCT-3'. The PCR conditions used were $30 \mathrm{~s}$ denaturation at $92^{\circ} \mathrm{C}$, annealing at $60^{\circ} \mathrm{C}$.

\section{Bioinformatics analysis}

Complexity analysis ${ }^{10}$ was applied to analyse the flanking sequences ( $\pm 25 \mathrm{bp}$ ) that encompassed each of the six identified SPRED1 mutations. Direct and inverted sequence repeats, as well as symmetric sequence elements, were sought. Mutational mechanism predicted to lead to microdeletions, micro-insertions and indel mutations mediated by these types of repeats have been described. ${ }^{11}{ }^{12}$ The possible mutational mechanism of single base pair substitutions mediated by direct repeats identified by means of complexity analysis was explored in this study in the context of slipped non-B DNA structure formation. ${ }^{13}{ }^{14}$

\section{RESULTS}

Germline SPRED1 mutations were identified in six of the 85 unrelated patients screened. These included three nonsense mutations (R16X, E73X and R262X), two frameshift mutations (2 bp del: c1048_1049 GG and 4 bp del: c1149_1152), and a single missense mutation (V44D). The c.1048-1049 GG frame shift mutation has been reported by Brems et al. ${ }^{6}$ The remaining 5 SPRED1 mutations are all novel sequence changes. The mutation and clinical details on the six families is given in table 2 and fig 1 . All the affected individuals had café-au-lait spots and none exhibited obvious Noonan-like features. None of the individuals had Lisch nodules or cutaneous neurofibromas.

All probands but one (in family 2) with a SPRED1 mutations satisfied the diagnostic criteria for NF1 (table 2), but none had any other NF1 associated clinical complications. No significant developmental or learning problems were observed, nor was macrocephaly evident.

The proband in family 1 sought medical opinion in his 20 s because of his marked periorbital pigmentation; while he was in his 30 s he had six café-au-lait spots randomly distributed on his back. He had extensive freckling over his upper trunk, both axillae and groins. In addition he had freckles in his forearm creases. On the right of his trunk, at waist level, there was a

Table 1 Primer sequence and polymerase chain reaction (PCR) conditions for SPRED2, SPRED3, SPRY1, SPRY2, SPRY3 and SPRY4

\begin{tabular}{|c|c|c|c|c|c|c|}
\hline Gene & Exon & PCR fragments & Forward primer $\left(5^{\prime}-3^{\prime}\right)$ & Reverse primer $\left(5^{\prime}-3^{\prime}\right)$ & $\begin{array}{l}\text { PCR temperature } \\
\text { ( } \mathrm{C})\end{array}$ & PCR buffer \\
\hline \multirow[t]{9}{*}{ Spred 2} & 1 & $1 \mathrm{a}$ & aggaagctttttgcactcca & gatagggtttgggggaagg & 65 & Failsafe D \\
\hline & & $1 b$ & cgtccccttcccaaatct & acgccaagttcacccaataa & 61 & Failsafe D \\
\hline & 2 & & tgccctgtgcttcttcttct & cccacgagttgtatgtctgc & 61 & $10 \times$ PCR buffer \\
\hline & 3 & & ttggtagttgccaccagtga & tactgacctggtcccaaacc & 61 & $10 \times$ PCR buffer \\
\hline & 4 & & tgcaaaaagaatggaatgtgg & acagcaacagcaaacactgc & 64 & $10 \times$ PCR buffer \\
\hline & 5 & & ttttgggaagagcagcaaat & taaaggcaggagcaggagag & 61 & $10 \times$ PCR buffer \\
\hline & 6 & $6 a$ & ggagaaggtggggtgttttt & ctttggggtcctcgccta & 61 & $10 \times$ PCR buffer \\
\hline & & $6 b$ & gaggtccccaagcatgacta & aaggcaataagagccatcca & 61 & Failsafe D \\
\hline & & $6 c$ & ggaccccgagggagactat & aagagacgagttcccctgtg & 61 & $10 \times$ PCR buffer \\
\hline \multirow[t]{4}{*}{ Spred 3} & 1 & & tgtgttgtccetgtccttcc & acctgacctctgctccacat & 61 & Failsafe D \\
\hline & $2+3$ & Exon $2+3$ together & atggacgagacgtcacagg & gcctgctacacagtaggtgct & 68 & Failsafe $\mathrm{E}$ \\
\hline & 4 & & gattctgagaagcgggaaga & acgtgggactggaggagatt & 61 & $10 \times$ PCR buffer \\
\hline & 1 & & ccctcctcctaccacagaga & gaaaagcccattttcaagca & 60 & $10 \times$ PCR buffer \\
\hline \multirow[t]{5}{*}{ Spry 1} & 2 & $2 a$ & ccccagcatcattgtaatcc & cgaggagcaggtcttttcac & 60 & $10 \times$ PCR buffer \\
\hline & & $2 b$ & tgctattttgtccttagaccaga & ggaacccttcaagtcatcca & 60 & $10 \times$ PCR buffer \\
\hline & & $2 c$ & ccagtccctggtcataggtc & ctaagcacatgcaggttcca & 60 & $10 \times$ PCR buffer \\
\hline & & $2 d$ & accatcctgtttggectgta & ggtgggaaacagggaaaaat & 60 & $10 \times$ PCR buffer \\
\hline & 1 & & acttggcgatctggctttag & caggaggggaagagccaaac & 60 & $10 \times$ PCR buffer \\
\hline \multirow[t]{6}{*}{ Spry 2} & 2 & 2.1 & attcaggtgggtggagagtg & agctgaccgtgcttatggat & 60 & $10 \times$ PCR buffer \\
\hline & & 2.2 & ctccactcagcacaaacacg & tggctggaaggtaacaccat & 60 & $10 \times$ PCR buffer \\
\hline & & 2.3 & gacaacccatgttcttgcag & gcctaggagtgtctgtgttgc & 60 & $10 \times$ PCR buffer \\
\hline & & 2.4 & cggtgaaatgctttttgtcc & ttttgccttacagaaagccttt & 60 & $10 \times$ PCR buffer \\
\hline & & 2.5 & tttgcaactgtgaaaaacaagt & gataaaagaagacaaaacagctcagt & 60 & Fail safe $C$ buffer \\
\hline & 1 & $1 \mathrm{a}$ & atgtgccctgaaatccatgt & actgcgggggagagaagtag & 60 & $10 \times$ PCR buffer \\
\hline \multirow[t]{4}{*}{ Spry 3} & & $1 b$ & tgtaaacaggccctctccag & tcagcttctcccttcagagc & 60 & $10 \times$ PCR buffer \\
\hline & & $1 \mathrm{c}$ & cttcaggccaatccatcatc & catcatcagtggagcagtgg & 60 & $10 \times$ PCR buffer \\
\hline & & $1 d$ & gctgagagcctcctcgatta & ggggactcgaaggagaaaag & 60 & $10 \times$ PCR buffer \\
\hline & 1 & & tgtgcccacccattcatag & tgagggaaggaacactgagg & 60 & $10 \times$ PCR buffer \\
\hline \multirow[t]{5}{*}{ Spry 4} & 2 & & taagtcaaggggagggtgtg & caggatatcaaaatccccagaa & 60 & $10 \times$ PCR buffer \\
\hline & 3 & $3 a$ & ggctcccaaggacctgat & ggtgacatcctggtcacagc & 60 & $10 \times$ PCR buffer \\
\hline & & $3 b$ & tagcctggccctgaccac & agcacaggcactcctggtt & 60 & $10 \times$ PCR buffer \\
\hline & & $3 c$ & aaatgcaaggagtgtgcatc & caggcaggtagcagagcag & 60 & $10 \times$ PCR buffer \\
\hline & & $3 d$ & ggtgctctctccgtggtg & ttcttagatgtcagaagagaacca & 60 & $10 \times$ PCR buffer \\
\hline
\end{tabular}


Table 2 Identification of SPRED1 mutations in six unrelated families. The nature and location of mutations along with the clinical features are listed

\begin{tabular}{|c|c|c|c|c|c|c|c|}
\hline \multirow[b]{2}{*}{ Patients } & \multirow[b]{2}{*}{ Gender, age } & \multirow[b]{2}{*}{ Germline mutation } & \multicolumn{5}{|c|}{ Clinical Features } \\
\hline & & & $\begin{array}{l}\text { Café-au- } \\
\text { lait spots }\end{array}$ & Freckling & $\begin{array}{l}\text { Lisch } \\
\text { nodules }\end{array}$ & Macrocephaly & Other associated features \\
\hline Family 1 & Male, 30 years & Exon: 8 & Present & Present & None & $\begin{array}{l}\text { Normal range (50th } \\
\text { centile) }\end{array}$ & Excessive periorbital pigmentation \\
\hline Family 2 & Male, 5-9 years & Exon: 8 & Present & Absent & None & $\mathrm{N} / \mathrm{A}$ & None \\
\hline Father & Male, 28 years & Exon: 8 & Present & Axillary & None & $\begin{array}{l}\text { Head circumf: normal } \\
\text { range }\end{array}$ & $\begin{array}{l}\text { Congenital soft tissue swelling on } \\
\text { scalp }\end{array}$ \\
\hline Son & Male, 6 years & c.784A > T: R262X & Present & Axillary and inguinal & None & & Inguinal haemangioma \\
\hline \multicolumn{8}{|l|}{ Family 4} \\
\hline Son & Male, 3 years & Exon: 4 & Present & Absent & None & Head circumf: 9th centile & \multirow[t]{2}{*}{ Protruding ears } \\
\hline Father & Male, 26 years & c. $217 \mathrm{G}>\mathrm{T}: \mathrm{E73X}$ & Present & Absent & None & Head circumf: 90th centile & \\
\hline \multicolumn{6}{|l|}{ Family 6} & & Father said to have CAL \\
\hline Grandfather & Male, $60-68$ years & Exon: 3 & Present & Present & N/A & Head circumf: 98th centile & \multirow[t]{4}{*}{ None } \\
\hline Father & Male, $30-35$ years & c. $131 \mathrm{~T}>\mathrm{A}: \mathrm{V} 44 \mathrm{D}$ & Present & Present & N/A & $\begin{array}{l}\text { Head circumf: normal } \\
\text { range }\end{array}$ & \\
\hline Son & Male, 4-7 years & & Present & $\mathrm{N} / \mathrm{A}$ & N/A & $\begin{array}{l}\text { Head circumf: normal } \\
\text { range }\end{array}$ & \\
\hline Daughter & Female, 2-4 years & & Present & present & N/A & & \\
\hline
\end{tabular}

CAL, café-au-lait; circumf, circumference; NA, information not available.

right sided segment of freckles. In his neck there was a very distinct cut off to his freckles. These last two features raised the possibility of mosaicism and he had been referred to our laboratory as a possible segmental NF1 patient.

In family 3, a 28-year old father and his 6-year-old son, identified with a SPRED1 nonsense mutation (R262X), both presented with café-au-lait spots and axillary freckling, with a soft tissue swelling of the scalp noted in the father from birth.

In family 4, the father and son were found to carry a nonsense mutation (E73X). The father's head circumference is on the 90th centile, height is between 50 th-75th centile and he has protruding ears. His 3 -year-old son has similar features but the head circumference is at the 9th centile.

In family 5 , the mother had six café-au-lait spots and freckling in the right groin. No Lisch nodules were detected and she was of normal intelligence. Her father was also reported to have café-au-lait spots. Her daughter also had café-au-lait spots and exhibited no other features of NF1.

SPRED1 mutation analysis in the four affected members from the three generation family 6 identified the same V44D SPRED1 missense mutation in each individual. This valine residue is known to be highly conserved. The clinical features in each affected individual included café-au-lait spots and axillary freckling but no cutaneous neurofibromas. The father had a head circumference on the 90 th centile but the head circumferences of the children were found to be in the normal range.

Several single nucleotide polymorphisms were also detected in the SPRED1 gene, most previously reported in the Entrez single nucleotide polymorphism (SNP) database. At least 10 patient DNA samples were homozygous for all SPRED1 polymorphisms and seven were also homozygous for an informative microsatellite marker. These samples will be tested with a multiplex ligation dependent probe amplification (MLPA) kit when it becomes available.
We failed to identify disease causing mutations in SPRED2, 3 and SPRY1-4 genes. Several polymorphic changes were identified in these genes. A possible SPRY1 missense alteration was identified in a similarly affected patient who was negative for both NF1 and SPRED1 mutations. This SPRY1 sequence change was not found on analysis of 100 normal chromosomes; however, as parental DNA samples for this sporadic case were unavailable, and without undertaking a suitable functional analysis, it is currently impossible to assess whether this is a disease-causing mutation or represents only a rare neutral variant.

Complexity analysis of the flanking sequences surrounding each SPRED1 mutation found inverted repeats adjacent to two of the single base pair substitutions (fig 2). Each inverted repeat, or palindrome, consists of a short sequence that is complementary to a second nearby sequence located upstream of the first one on the same DNA strand. Such inverted repeats can form hairpin loop structures, and thus any base mismatch in such a structure may promote aberrant templating that can lead to the formation of a more stable hairpin loop structure. A schematic explanation of the SPRED1 mutation T $>$ A [V44D] in exon 3 of the gene is shown in fig $3 a$.

Short direct sequence repeats were found adjacent to the two frameshift deletions (fig 2), and such repeats are reported to be involved in microdeletion formation in several human genetic diseases. ${ }^{12}$ Direct repeats were also found in the vicinity of two nonsense mutations (E73X, R262X), with such direct repeats capable of forming non-B DNA slipped structures formation as shown in fig $3 b$. The misaligned slipped structures illustrated may template a nucleotide change creating a perfect WatsonCrick base pairing.

\section{DISCUSSION}

Although no evidence for locus heterogeneity in classical NF1 families has been found, some families with the "café-au-lait 

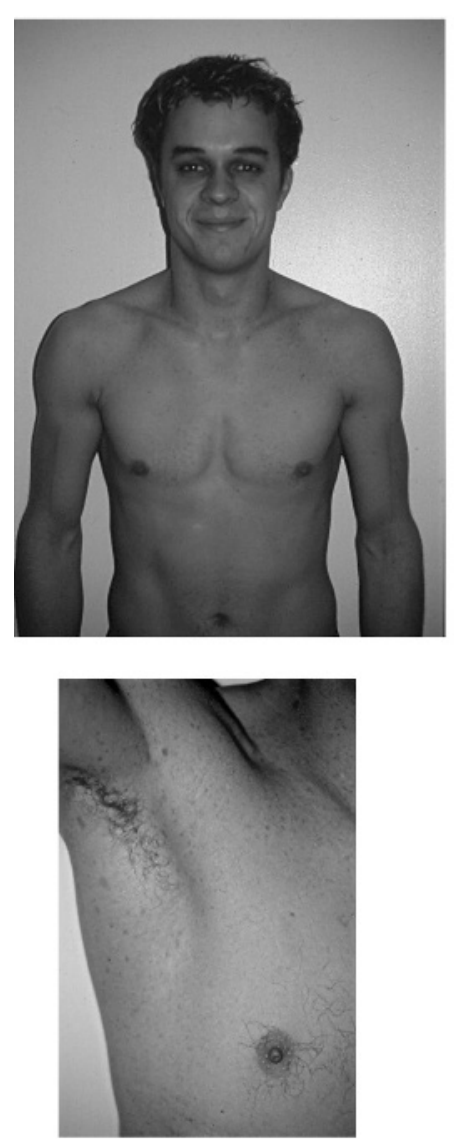

Family 1
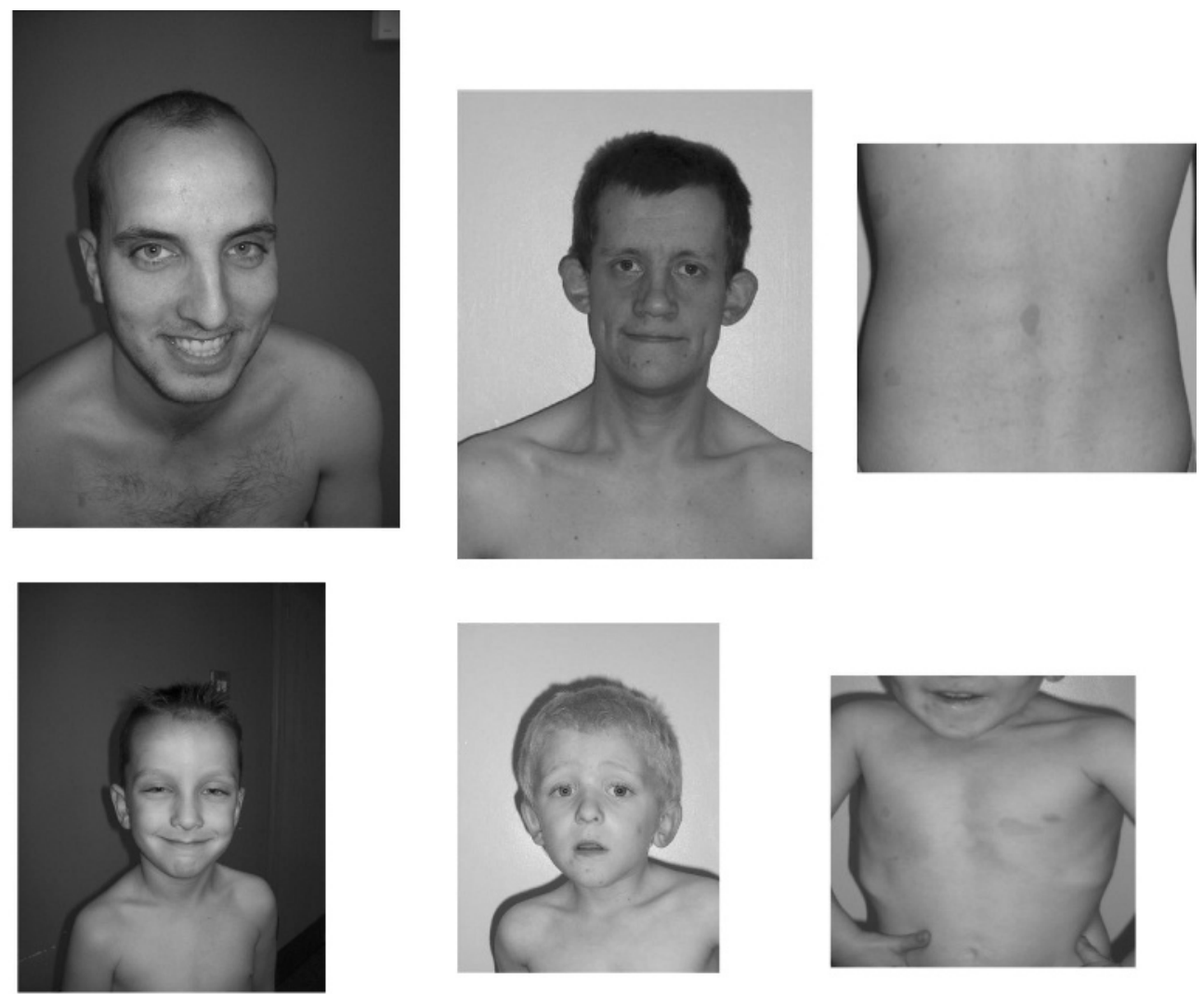

Family 3

\section{Father and son}

only" phenotype were reported to be unlinked to the NF1 gene region at $17 \mathrm{q} 11.2,{ }^{15}$ None of these families were large enough to permit a genome-wide mapping study. The recent identification of mutations of the 15q14-located SPRED1 gene in patients with this phenotype ${ }^{6}$ is therefore the first indication of an alternative disease locus. The present study confirms these findings by identifying six SPRED1 mutations, five novel, in 85 unrelated minimally affected patients, most of whom still satisfy the diagnostic criteria for NF1. A SPRY1 missense alteration was found in a similarly affected patient negative for both NF1 and SPRED1 mutations, although whether this is a disease-causing mutation, or only a rare neutral variant, remains to be established. Overall SPRED1 mutations apparently account for $\sim 10 \%$ of patients with a mild NF1 phenotype in the two cohorts reported (Brems et $\mathrm{al}^{6}$ and the present study) to date. This has major implications for counselling NF1 familiesthe mild pigmentary phenotype is clinically indistinguishable from NF1 in childhood and the absence of major physical complications and neurofibromas greatly reduces any NF1 disease related morbidity, especially in adults.

The main feature exhibited by all these patients was the presence of multiple café-au-lait spots, with skinfold freckling also evident in most cases, but with no other NF1 features. The current National Institutes of Health (NIH) diagnostic criteria for NF1 were met in five of the six probands. In children, the main clinical distinguishing feature between NF1 and SPRED1 cases appears to be the lack of Lisch nodules and major physical complications. In contrast to the patients reported by Brems et $a l,{ }^{6}$ none of the patients in this series had macrocephaly, learning problems or significant facial dysmorphism, although one of our patients had the periorbital pigmentation seen in many NF1 adults. In family 3, the underlying pathogenesis of the associated large haemangioma observed in the patient is difficult to explain. Such vascular abnormalities are more of a cardinal feature found in another RAS-MAPK syndrome resulting from mutations of the RASA1 gene. The RASA1 protein is another GTP-ase activating protein that also downregulates the activated RAS signalling pathway, a function similar to that of neurofibromin. However, constitutional heterozygous RASA1 mutations are associated with an autosomal dominant phenotype presenting with capillary malformations/arteriovenous malformations. ${ }^{15}$

At a recent European NF group meeting it was agreed that the clinical phenotype resulting from SPRED1 mutations should be referred to as Legius syndrome in recognition that the group led by Professor Eric Legius defined this phenotype at the clinical and molecular level. ${ }^{6}$ It will be important to pool clinical data from different centres to document the variability in phenotype and natural history of Legius syndrome.

The confidence of clinical diagnosis in the majority of NF1 cases, coupled with the cost and complexity of current NF1 mutation analysis, means that application of molecular testing 
Figure 2 Different types of repeat that could have mediated missense and nonsense mutations and short deletions in the SPRED1 gene. Direct repeats are underlined, inverted repeats are shaded and indicated by the arrows mutated nucleotides are shown in bold upper case letters.
Nonsense mutation $\mathrm{c} 217 \mathrm{G}>\mathrm{T}: \mathrm{E} 73 \mathrm{X}$ [GAA $>$ TAA] direct repeats

atttggctttgtcagGTGGTTTTGGAATGTATGCTTAAAAAAGTCACT

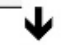

atttggctttgtcagGTGGTTTTGTAATGTATGCTTAAAAAAGTCACT

Nonsense mutation c784 A>T R262X direct repeats

TCTTAATACGTCGCTATGCAGACTACAGACATCCTGACATGTGGAAAAAT

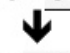

TCTTAATACGTCGCTATGCAGACTACTGACATCCTGACATGTGGAAAAAT

G350fsX9 2 bp deletion c. 1048-1049 direct repeats
AGGTTTAATCATGAAGAAAATGTAAGGGAAATGTCAGGATGCTCC
AGGTTTAATCATGAAGAAAATGTTA

S383fsX21 Mutation 4 bp deletion c.1149-1152 imperfect direct repeats TGTTGTATCATTGTATGTCAGACTCAGAGGGAGATTTTCTGATCCCTGTTCGTG $\downarrow$ deletion

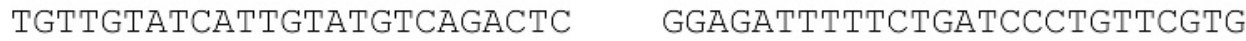

Nonsense mutation $\mathrm{c} 46 \mathrm{C}>\mathrm{T}: \mathrm{R} 16 \mathrm{X}$ inverted repeats

ATTTTAGTAATAGTTATGCACGAGTGCGAGCTGTGGTGATG

AttTtAgtAATAGTtATGCATGAGTGCGAGCTGTGGTGATG

Missense mutation Exon $3 \mathrm{~T}>\mathrm{A}$ : Val44Asp inverted repeats

TGGACTAAGCAGCGTCACTGTCTTCAAAGTCCCTCATCAGG

TGGACTAAGCAGCGTCACTGACTTCAAAGTCCCTCATCAGG is often not part of routine NF1 care. There are now, however, three genotype/phenotype correlations of major clinical significance. These are the large NF1 microdeletion phenotype, that is often associated with a much more severe disease format, ${ }^{1}$ the specific 3 bp deletion of exon 17 of the NF1 gene, ${ }^{5}$ and now mutations of the 15q14 located SPRED1 gene, both associated with NF1 patients exhibiting a generally milder clinical phenotype. ${ }^{6}$ Such findings strongly suggest that routine NF1 genetic testing should be implemented, especially for sporadic cases. From a research perspective, the majority of patients with a mild phenotype, in both this and the previous study, apparently had neither an NF1 nor a SPRED1 gene mutation, emphasising the need to expand the search for causative gene mutations to other related genes in the Ras/ MAPK pathway. The possibility that some of the NF1/SPRED1 mutation negative cases might be mosaics for an NF1 mutation also needs exploration. ${ }^{16}$ However, we cannot exclude the possibility of mutations in those regions of both the NF1 and SPRED1 genes not currently screened in our genetic analyses. Indeed, the mutation detection rate for the NF1 gene, even in classical NF1 patients, is reported to vary from $50-95 \% .{ }^{17-23}$
The Spred proteins contain several specific functional domains, including an N-terminal EVH1 domain, a central cKit binding domain (KBD), and a C-terminal Sprouty-like cysteine-rich domain (SPR domain) that is also present in the Sprouty proteins, although the N-terminal domain is more variable but does contain a conserved $\mathrm{SH} 2$ domain binding motif with a central tyrosine residue. ${ }^{6-9}$ All these proteins do, however, function as Ras/MAPK signalling pathway inhibitors. Three of the identified mutations in this study (G350FsX9, S383FsX21 and R262X) are located within the C-terminal SPR domain known to interact with Raf proteins to make them inaccessible to Raf kinase phosphorylation when associated in this Spred-Raf complex. ${ }^{7}$

The nature of the damage may depend upon the frequency and types of mutations which, in turn, depend on the sequence context. A number of sequence repeats in the adjacent SPRED1 gene coding region were predicted to have mediated some of the observed mutational changes. In vitro studies of various alternative conformations ${ }^{13}{ }^{14}$ have shown that non-B DNA structures are mutation prone. Here we propose a potential mutational mechanism underlying single base pair substitutions 
Figure 3 Schematic representation of potential mutational mechanism underlying nonsense mutation $\mathrm{G}>\mathrm{T}: \mathrm{E} 73 \mathrm{X}$ [GAA $>$ TAA, c217] and missense mutation $\mathrm{T}>\mathrm{A}$ : V44D. (a)

Normal sequence before mutation : atttggcttttgtcagGTGGTTTTGGAATGTAT . . .

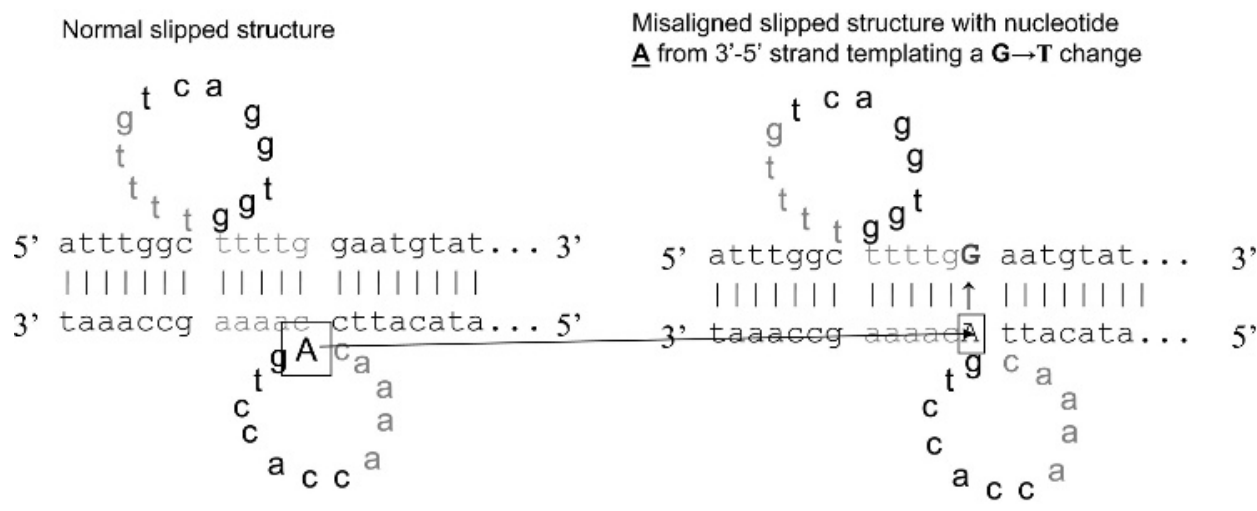

A slipped structure intermediate is formed by the direct repeats the $\mathbf{G} \rightarrow \mathbf{T}$ nucleotide change.

Mutated sequence: atttggcttttgtcagGTGGTTTTGTAATGTAT . .

(b)

Normal sequence before mutation : tggactaagcagcgtcactgTcttcaaagtccct...

Predicted that a 'hairpin loop' structure formed by interaction between the imperfe inverted repeats gTctt and aagtc may have templated the $\mathrm{t} \rightarrow \mathrm{A}$ nucleotide change that resulted in this missense mutation

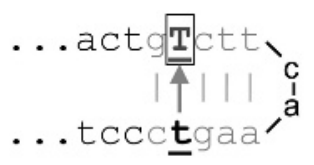

Missense mutated sequence : tggactaagcagcgtcactgA-Acttcaaagtccct... and involving two direct repeats capable of a temporary misaligned non-B slipped structure formation which may lead to a nucleotide change.

In summary, a cohort of NF1-like disease patients, consisting of individuals with just café-au-lait spots and axillary freckling, but no cutaneous neurofibromas or Lisch nodules, and without any detectable NF1 mutations, has been identified. Among these patients, several individuals with different SPRED1 mutations have been identified. As no other gene mutations were discovered, despite extensively screening for coding region mutations of the NF1, SPRED1-3 and SPRY1-4 genes, it remains a challenge to define the molecular basis of the disease in these patients. It is possible that extending such comprehensive mutation analyses to many more of the genes involved in the RAS/MAPK signalling pathway ${ }^{24} 25$ may provide further information in this group of mildly affected patients.

Acknowledgements: We sincerely thank all the clinicians who referred patients for this study and all the patients and their families included in this study, particularly Dr Debbie Shears for updated information on family 1 . We gratefully acknowledge the technical assistance of Laura Elizabeth Thomas. We thank Dr lan Frayling and Dr A Rawlinson for their support.

Funding: We thank Cancer Research UK and INSERM for their generous financial support

Competing interests: None declared.

Patient consent: Obtained

\section{REFERENCES}

1. Huson SM. The neurofibromatosis: classification, clinical features and genetic counselling. In: Kaufmann D, ed. Neurofibromatoses. Basel: Karger, 2008:16:1-20

2. Upadhyaya M, Cooper DN. Neurofibromatosis type 1 from genotype to phenotype. Oxford: BIOS Scientific Publishers Limited, 1998.

3. Cichowski K, Jacks T. NF1 tumor suppressor gene function: narrowing the GAP. Cell 2001;:104:593-604.

4. Bennett $\mathbf{E}$, Thomas $\mathrm{N}$, Upadhyaya M. Neurofibromatosis type 1: its association with the Ras/MAPK pathway syndromes. J Pediatr Neurol 2009;7:105-15.

5. Upadhyaya M, Huson SM, Davies M, Thomas N, Chuzhanova N, Giovannini S, Evans DG, Howard E, Kerr B, Griffiths S, Consoli C, Side L, Adams D, Pierpont M, Hachen R, Barnicoat A, Li H, Wallace P, Van Biervliet JP, Stevenson D, Viskochil D, Baralle D, Haan E, Riccardi V. Turnpenny P, Lazaro C, Messiaen L. An absence of cutaneous neurofibromas associated with a 3-bp inframe deletion in exon 17 of the NF1 gene 
(c.2970-2972 delAAT): evidence of a clinically significant NF1 genotype-phenotype correlation. Am J Hum Genet 2007;80:140-51.

6. Brems H, Chmara M, Sahbatou M, Denayer E, Taniguchi K, Kato R, Somers R, Messiaen L, De Schepper S, Fryns J-P, Cools J, Marynen P, Thomas G, Yoshimura A, Legius E. Germline loss-of-function mutations in SPRED1 cause a neurofibromatosis 1 like phenotype. Nat Genet 2007;39:1120-6.

7. Wakloka T, Sasaki A, Kato R, Takanori S, Matsumoto A, Miyoshi K, Tsuneoka M, Komlya S, Baron R, Yoshimura A. Spred is a sprouty-related suppressor of Ras signalling. Nature 2001;412:647-51.

8. Katoh Y, Katoh M. FGF signalling inhibitor, SPRY4, is evolutionarily conserved target of WNT signalling pathway in progenitor cells. Int J Mol Med 2006;17:529-32.

9. Bundschu K, Walter U, Schuh S. Getting a first clue about SPRED functions. BioEssays 2007;29:897-907.

10. Gusev VD, Nemytikova LA, Chuzhanova NA. On the complexity measures of genetic sequences. Bioinformatics 1999:15:994-9.

11. Chuzhanova NA, Anassis EJ, Ball E, Krawczak M, Cooper DN. Meta-analysis of indels causing human genetic disease: mechanisms of mutagenesis and the role of local DNA sequence complexity. Hum Mutat 2003:21:28-44.

12. Ball EV, Stenson PD, Krawczak M, Cooper DN, Chuzhanova NA. Micro-deletions and micro-insertions causing human genetic disease: common mechanisms of mutagenesis and the role of local DNA sequence complexity. Hum Mutat 2005; 26:205-13

13. Bacolla A, Jaworski A, Larson JE, Jakupciak JP, Chuzhanova N, Abeysinghe SS, O'Connell CD, Cooper DN, Wells RD. Breakpoints of gross deletions coincide with nonB DNA conformations. Proc Natl Acad Sci USA 2004;101:14162-7.

14. Bacolla A, Wells RD. Non-B DNA conformations, genomic rearrangements, and human disease. J Biol Chem 2004;279:47411-14.

15. Eerola I, Boon LM, Muliken JB, Burrows PE, Domomartin A, Watanabe S, Vanwiick R. Vikkula M. Capilaary malformation-arteriovenous malformation, a new clinical and genetic disorder caused by RASA1 mutations. Am J Hum Genet 2003;73:1240-9.
16. Maertens 0, De Schepper S, Vandesompele J, Brems H, Heyns I, Janssens S, Speleman F, Legius E, Messiaen L. Molecular dissection of isolated disease features in mosaic neurofibromatosis type 1. Am J Hum Genet 2007;2:243-51.

17. Shen MH, Harper PS, Upadhyaya M. (1993) Neurofibromatosis type 1(NF1): the search for mutations by PCR-heteroduplex analysis on Hydrolink gels. Hum Mol Genet 2003:2:1861-4

18. Upadhyaya M, Shaw DJ, Harper PS. Molecular basis of neurofibromatosis type 1 (NF1): mutation analysis and polymorphisms in the NF1 gene. Hum Mut 2003:4:83-101.

19. Osborn M, Upadhyaya M. Evaluation of protein truncation test for mutation detection in the NF1 gene: mutational analysis of 15 known and 40 unknown NF1 mutations with the identification of 14 novel mutations. Hum Genet 1999:105:327-32

20. Messiaen LM, Callens T, Mortier G, Beysen D, Vandenbroucke I, Van Roy N, Speleman F, De Paepe A. Exhaustive mutation analysis of the NF1 gene allows identification of $95 \%$ of mutations and reveals a high frequency of unusual splicing defects. Hum Mutat 2000;15:541-55

21. Ars E, Kruyer H, Morell M, Pros E, Serra E, Ravella A, Estivill X, Lazaro C. Recurrent mutations in the NF1 gene are common among neurofibromatosis type 1 patients. $J$ Med Genet 2003:40:e82.

22. Han S, Cooper DN, Upadhyaya M. Evaluation of denaturing high performance liquid chromatography (DHPLC) for mutational analysis of the neurofibromatosis type 1 (NF1) gene. Hum Genet 2000;109:487-97.

23. Schubbert S, Shannon K, Bollag G. Hyperactive Ras in developmental disorders and cancer. Nat Rev Cancer 2007;7:295-308.

24. Bentires-Alj M, Kontaridis M, Neel B. Stops along the RAS pathway in human genetic disease. Nat Med 2006;12:283-5.

25. Denayer $\mathbf{E}$, de Ravel T, Legius E. Clinical and molecular aspects of Ras related disorders. J Med Genet 2008:45:694-703.

\section{BMJ Careers Fair}

\section{2-3 October 2009, Business Design Centre, London, UK}

9-10 October 2009, Thinktank, Birmingham, UK

$\mathrm{BMJ}$ is the largest organiser of medical recruitment fairs across the UK. This year we are organising two careers fairs, in partnership with the London Deanery on 2-3 October in London, and the West Midlands Deanery on 9-10 October in Birmingham.

Whatever your grade or specialty there is a careers fair for you. You can:

- attend seminars on topics such as CV writing, interview skills, planning your career and working abroad

- visit exhibition stands to get careers advice, find a new job, identify alternative career pathways

It's free to attend the exhibition if you register online in advance. There is a small fee for attending our seminar programme.

Register online today at www.careersfair.bmj.com 